\title{
Taste Responsiveness in Eating Disorders
}

\author{
ADAM DREWNOWSKI ${ }^{a}$ \\ Program in Human Nutrition \\ School of Public Health \\ and \\ Department of Psychiatry \\ Medical School \\ University of Michigan \\ Ann Arbor, MI 48109-2029
}

Patients with anorexia or bulimia nervosa suffer from disturbances in body weight and nutritional status. Anorexia nervosa is characterized by extreme caloric restriction, avoidance of starches and fats, and a variety of metabolic and neuroendocrine dysfunctions associated with a severe loss of body weight. ${ }^{1,2}$ Bulimia nervosa is characterized by uncontrollable eating binges that may be countered by fasting, purging, vomiting, or excessive physical exercise..$^{3.4}$ Patients with a combined diagnosis of anorexia nervosa with bulimia alternate periods of near starvation with recurrent eating binges that are followed by purging or self-induced vomiting to lose weight. ${ }^{5-7}$

Both anorexia and bulimia nervosa represent nutritional as well as psychiatric disorders ${ }^{8-10}$ Characteristic patterns of food aversion and uncontrollable food cravings have been linked to the patients' nutritional or metabolic status. ${ }^{11-13}$ Evidence is growing that uncontrollable binges are triggered by physiological events, and that food aversions may also have a psychobiological basis. Both physiological abnormalities and psychopathology can be reversed following weight regain and the resumption of normal eating habits. ${ }^{14}$

Taste responsiveness may have a role in mediating food preferences and diet choices of eating disorder patients. ${ }^{15,16}$ Some studies suggest that taste functioning of eating disorder patients is characterized by dysgeusia or hypogeusia. ${ }^{17,18}$ Prolonged calorie malnutrition and endocrine abnormalities in anorexia nervosa may lead to dysfunctions in taste and smell that depress appetite and contribute to food aversions. Chronic vomiting in bulimia nervosa reduces salivary flow, lowers oral $\mathrm{pH}$, and may lead to a loss of taste sensitivity or sensory functioning. ${ }^{19,20}$

Hedonic aspects of taste responsiveness may also underlie food cravings or food aversions. Anorectic patients profess to dislike sugars and starches and show a calculated avoidance of sweets and desserts. ${ }^{8.21}$ However, this phenomenon, sometimes known as "carbohydrate phobia," patients may consume vast quantities of sweets and desserts in the course of an eating binge. Recent clinical studies have further shown that both anorectic and bulimic women like the taste of intensely sweet solutions presented in the form of not-to-be-ingested taste stimuli. ${ }^{16}$ More recent reports based on analysis of cognitive structure ${ }^{23}$ indicate

${ }^{a}$ Address for correspondence: Dr. Adam Drewnowski, School of Public Health M-5170, University of Michigan, Ann Arbor, MI 48109-2029. 
that anorectic women tend to avoid foods they view as high in calories, that is, foods rich in fat. Consequently, there is some question whether the pattern of food choice in anorexia nervosa is better described in terms of fat avoidance or carbohydrate phobia. This review examines food selection patterns in patients with eating disorders, focusing on the nature of sensory preferences for sugar and fat.

\section{FOOD CHOICES IN EATING DISORDERS}

It is commonly believed that anorectic women reject starchy, fattening foods and avoid all carbohydrates, particularly sugar. In reality, dietary intakes in anorexia nervosa can be highly variable. Anorectic patients show many idiosyncratic food choices that may include vegetarianism, avoidance of red meat dishes, and abstinence from some dairy products, sweets and desserts. ${ }^{\mathbf{3 , 8 , 1 0 . 2 4}}$ According to some reports, anorectics are willing to eat vegetables, lettuce, fresh fruit, cheese, and sometimes eggs, but avoid carbohydrates and are disgusted by milk and meat. ${ }^{3,8}$

While some anorectic patients eat diets lacking in basic nutrients, others consume a balanced diet, choosing to restrict calories by eating irregularly, or by severely restricting intake at each meal. ${ }^{25}$ Although many anorectics seem to consume mostly vegetables and fruit, the macronutrient content of the typical anorectic diet is open to question. Early studies of hospitalized patients ${ }^{8}$ revealed a mean intake of 1,031 $\mathrm{kcal} / \mathrm{day}$, with carbohydrates providing only $33 \%$ of total daily calories, fat providing $49 \%$, and protein $18 \%$. However, another study ${ }^{10}$ based on 24 -hour food recalls reported that anorectic patients ate a normal amount of carbohydrate but ate significantly less fat than normal-weight controls.

Anorectic patients often allow themselves to eat only healthy or nutritious foods, and avoid foods perceived as high in calories or rich in fat. ${ }^{23.24}$ However, such caloriedense foods are often the mainstay of eating binges, often defined as the ingestion of large amounts of easily digestible, high-calorie foods consumed in a short space of time. ${ }^{26}$ Some investigators have argued that all binges consist of carbohydrate-rich foods, consumed by bulimic women in an attempt to rectify underlying abnormalities in serotonin metabolism. ${ }^{27}$ However, as dietary assessment studies show, the macronutrient content of eating binges can again be highly variable.

According to some clinical reports, typical binge foods were bread, cakes, chocolate, yogurt, or cottage cheese. ${ }^{3}$ The patients were reported to eat up to $7 \mathrm{lb}$ of food and the magnitude of an eating binge was estimated at 15-20,000 kcal. More recent studies have estimated an average binge at $3,415 \mathrm{kcal}$ (range 1,200-11,500 cal) consumed within 1.2 hours. ${ }^{28}$ Observations of hospitalized bulimic women ${ }^{29}$ placed the average amount eaten per binge at 4,394 $\mathrm{kcal}$ (range 1,436-8,585 $\mathrm{kcal}$ ), and mean binge duration at just under one hour.

The chief binge foods seem to include ice cream, bread, candy, doughnuts, soft drinks, salads and sandwiches, cookies, popcorn, milk, cheese, and cereal. ${ }^{28}$ Bulimic patients monitored in a hospital setting mostly consumed doughnuts, pies, sandwiches, chocolate candy, and carbonated beverages. ${ }^{29}$ In contrast, eating bouts not classified as binges included salads, vegetables and fruit, and diet soft drinks. According to some reports, eating binges typically included high fat, moderate carbohydrate, and lowprotein foods. ${ }^{28.29}$ Other studies estimated binge composition at approximately $50 \%$ carbohydrate, $40 \%$ fat, and $10 \%$ protein. ${ }^{30}$ However, none of the studies distinguished between complex carbohydrates and simple sugars: It is likely that some binges are high in sweet, sugar-rich foods. 
Although many binges do include dessert-type foods, the notion of what constitutes a binge may be highly subjective. Eating episodes that include snacks or desserts are often described as binges: The consumption of forbidden sweet foods is typically associated with guilt, anxiety, and a desire to vomit. ${ }^{31}$ In contrast, meals consisting of vegetables and fruit may not be seen as binges. Self-reports of binge-eating may therefore be subject to attitudinal bias: reported binge frequency may be influenced by what was eaten rather than how much.

Furthermore, bulimic women are not the only group binging on carbohydrate-type snacks. College students who binged made comparable food choices, snacking on pastries, breads, and cookies, as well as other "junk food" items, including salted snacks, pretzels, or potato chips. ${ }^{32}$ Quite simply, many commercially available, prepackaged snacks tend to be high-carbohydrate foods that are also high in fat content. Snacking on protein-fat combinations was mentioned less often: Some college men but no women reported binging on hamburgers. ${ }^{32}$

It should also be noted that many snack-type foods tend to be mixtures of only two ingredients: sugar and fat. Although chocolate, cookies, or ice cream are generally regarded as high-sugar and therefore carbohydrate-rich foods, most of their calories are derived from fat rather than carbohydrate. ${ }^{33}$ Moreover, the chief carbohydrate present is simple sugar. The nutritional content of selected "carbohydrate-rich" snacks is summarized in TABLE 1. It can be seen that fat and sugar are the principal ingredients, accounting in some cases for up to $98 \%$ of snack calories.

\section{PHYSIOLOGICAL ASPECTS OF EATING BINGES}

Several investigators believe that eating binges are triggered by physiological events. According to some clinical studies, patients seemed to know that a binge was imminent, and there are reports of buying, hoarding, and preparing foods. ${ }^{34}$ Binges typically occurred during the early afternoon or evening, and reported precipitating events included tension, being alone, craving specific foods, thinking of food, or actually eating something. ${ }^{34}$

The taste of food may play a central role in binge-eating behavior. Bulimic patients report that they eat too quickly during a binge to taste anything. ${ }^{34} \mathrm{However}$, all patients feel that the taste and texture of food is important, at least at the beginning of the binge. Often the foods of choice are soft, milky, fluid foods that have connota-

TABLE 1. Composition of Selected Snack Foods

\begin{tabular}{lrrrr}
\hline \multicolumn{1}{c}{ Snack Food } & \multicolumn{3}{c}{ Kilocalories } & $(\mathrm{S}+\mathrm{F}) / \mathrm{T}^{a}$ \\
\cline { 2 - 4 } & Total & Sugar & Fat & $\mathbf{( \% )}$ \\
\hline M\&M/Mars chocolate candies (package) & 237 & 109 & 123 & 98 \\
Hershey dark chocolate (bar) & 222 & 80 & 108 & 85 \\
Nestle Crunch bar (bar) & 156 & 60 & 72 & 85 \\
Hostess chocolate cupcake (1 cake) & 160 & 60 & 52 & 70 \\
Pepperidge Farm Geneva (1 cookie) & 63 & 16 & 36 & 82 \\
RJR Nabisco Oreo (1 cookie) & 52 & 16 & 18 & 66 \\
Ice cream (16\% fat) (1 scoop) & 122 & 39 & 80 & 98 \\
\hline
\end{tabular}

${ }^{a}$ Kilocalories from sugar and fat as a percentage of total kilocalories. 
tions of high caloric density, satisfaction, and satiety. ${ }^{29}$ The drinking of noncaloric soft drinks and eating softer foods (e.g., ice cream) toward the end of a binge may also facilitate vomiting, which is usually planned ahead of time.

\section{TASTE-RESPONSIVENESS STUDIES}

Clinical studies on eating disorders have only recently begun to focus on the interaction between nutritional status, taste responsiveness, food preference, and diet selection. ${ }^{14,13}$ Among clinical features of anorexia nervosa, some of which are secondary to malnutrition, are endocrine abnormalities, reduced basal metabolic rate, hypokalemia, and impaired regulation of water balance. ${ }^{1,2,33}$ Protein and carbohydrate metabolism is said to be relatively preserved, and fasting blood glucose and insulin levels are lownormal or low. Abnormalities in lipid metabolism include hypercholesterolemia, and elevated $\beta$-hydroxybutyrate and plasma free fatty acid levels. ${ }^{33}$ Because anorectic patients often take vitamin and mineral supplements, zinc, copper, iron, and folic acid have been reported as normal in some studies but not in others. ${ }^{16,36}$

The number of studies on taste psychophysics in anorexia nervosa has been very limited. One study systematically examined the role of trace metals, vitamins, and other biochemical parameters in relation to taste function. ${ }^{36}$ The majority of anorectic patients had subnormal taste acuity for sour and bitter substances; taste acuity for salt and sweet was less disturbed. However, taste recognition scores failed to correlate with plasma zinc levels. ${ }^{36}$ In a more recent study examining responses to the four basic tastes, a majority of women with anorexia or bulimia nervosa showed evidence of hypogeusia or dysgeusia. ${ }^{16}$ Taste functioning improved substantially following weight regain to more than $85 \%$ of normal body weight. Although serum zinc and iron of eating disorder patients were depressed, they again failed to correlate with taste recognition and dysgeusia scores. ${ }^{16}$

Normal-weight bulimic patients show little evidence of nutritional trauma, and carbohydrate metabolism is largely intact. ${ }^{9}$ However, potential medical complications of binging and vomiting include electrolyte imbalance, erosion on the lingual surfaces of maxillary anterior teeth, pulp exposure, and swollen salivary glands. The consumption of sweet snacks, reduced buffering capacity of saliva, and low oral $\mathrm{pH}$ may lead to increased incidence of dental caries. ${ }^{19}$ Recent studies of anorectic and bulimic women ${ }^{18}$ showed lower magnitude estimate scores for the four basic tastes. The effect was most pronounced for hydrochloric acid, suggesting an impaired gustatory sensitivity for sour. Studies with normal-weight bulimics show a definite loss of sensation in sour receptors on the soft palate: Reflux of vomit damages taste receptors in this area. Taste distortions may be the consequence of chronic vomiting in bulimia nervosa.

\section{TASTE HEDONICS: SUGAR AND FAT}

Studies on hedonic aspects of taste responsiveness in anorexia and bulimia nervosa have focused on sensory perception and preferences for sugar and fat. ${ }^{15,37}$ The subjects were young women with a diagnosis of anorexia nervosa (restrictor), anorexia with bulimia, and bulimia nervosa, as well as a volunteer group of normal-weight controls. As summarized in TABLE 2, all clinic patients were tested twice, before and after dietary treatment and a substantial gain in body weight. The stimuli were 20 different mixtures of milk, cream and sugar, containing a range of sugar (0-20\% sucrose) and fat levels (0-52\% fat). 
TABLE 2. Subject Weights Pre- and Post-Treatment ${ }^{a}$

\begin{tabular}{|c|c|c|c|c|c|}
\hline \multirow[b]{2}{*}{ Group } & \multirow[b]{2}{*}{$\begin{array}{l}\text { Age } \\
(\mathrm{yr})\end{array}$} & \multicolumn{2}{|c|}{ Pretreatment } & \multicolumn{2}{|c|}{ Post-Treatment } \\
\hline & & $\begin{array}{l}\text { Weight } \\
\text { (kg) }\end{array}$ & $\underset{\left(\mathrm{kg} / \mathrm{m}^{2}\right)}{\mathrm{BMI}}$ & $\begin{array}{l}\text { Weight } \\
\text { (kg) }\end{array}$ & $\frac{\mathrm{BMI}}{\left(\mathrm{kg} / \mathrm{m}^{2}\right)}$ \\
\hline Anorectic & 17 & 40.5 & 15.5 & 49.7 & 19.0 \\
\hline Bulimic & 19 & 56.8 & 21.3 & 57.4 & 21.6 \\
\hline Normal weight & 19 & 57.8 & 21.1 & - & - \\
\hline
\end{tabular}

${ }^{a}$ From Drewnowski et al. ${ }^{16}$ Reprinted by permission.

The subjects followed the standard sip-and spit technique and were asked to rate the perceived intensity of sweetness, fatness, and creaminess of the stimuli. They also assigned an overall hedonic preference rating to each sample. ${ }^{38-40}$ No deficiencies in taste perception for these suprathreshold stimuli were observed between anorectic and bulimic women and normal-weight volunteer controls. Intensity estimates of sweetness and fat content increased as logarithmic functions of sucrose or fat concentration, and no differences in sensory evaluation were observed between patients with eating disorders and the comparison group. These data complement previous studies on taste perception in human obesity, where no differences in sweetness perception were observed between normal-weight, obese, or dieting individuals. ${ }^{41}$ It should be noted that this study involved the perception of recognizable sweet stimuli, and combined sweet taste perception with oral sensory evaluation of stimulus texture.

Significant differences between subject groups were observed in hedonic preference scores for mixtures of sugar and fat. Anorectic restrictor and anorectic bulimic patients showed elevated preferences for sweet taste and sharply reduced preferences for the oral sensation of fat relative to the comparison group. Stimulus optimization procedures involving the response surface method (RSM) determined that eating disorder patients optimally liked stimuli containing $16.5 \%$ fat and $12.7 \%$ sugar. In contrast, control subjects preferred stimuli that were richer in fat $\mathbf{( 2 8 . 7 \% )}$ ) but were somewhat less sweet $(9.1 \%$ sucrose). Three-dimensional projections of the hedonic response surface, and the corresponding isohedonic contours are shown in FIGURE 1.

Hedonic responsiveness as measured by the optimally preferred sugar/fat ratio was negatively correlated with the subjects' body fatness - as measured by the body mass index $\left(w t / h t^{2}\right)$. The most underweight subjects showed the highest sensory responsiveness to sweet taste. However, body weight is not the only factor influencing taste responsiveness. A recent study has shown that normal-weight bulimic women presented with samples of sweetened soft, dessert-type white cheese preferred stimuli that were sweeter but lower in fat content than those selected by normal-weight female controls. ${ }^{38}$

\section{TASTE HEDONICS AND BODY WEIGHT}

The hedonic response to sweet taste has long been regarded as a useful index of metabolic status or physiological "set-point." Calorie-deprived subjects maintaining body weight below set-point by virtue of constant dieting are expected to find sweet solutions extremely pleasant, a finding reported in some studies, though not in others. ${ }^{42,43}$

The present finding that underweight subjects show elevated preferences for sweet taste seems consistent with the set-point hypothesis. However, as seen in Figure 2, this pattern of response remained stable even following six to eight weeks of dietary therapy and weight regain to target levels. ${ }^{16}$ Optimally preferred levels of sugar and 
VOLUNTEER CONTROLS

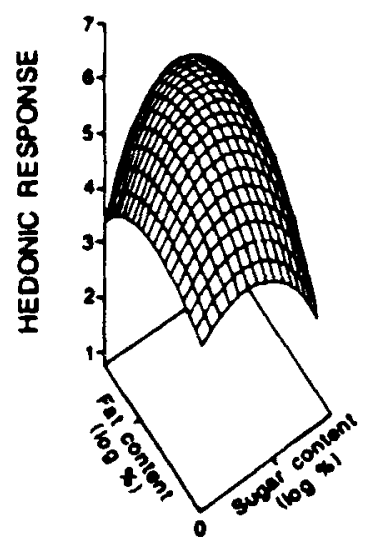

VOLUNTEER CONTROLS

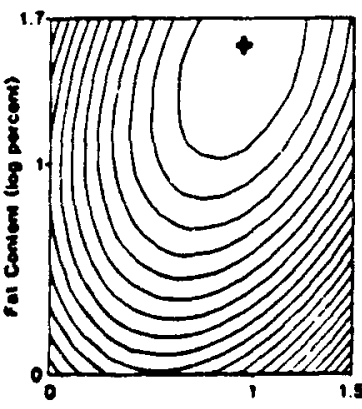

BULIMK

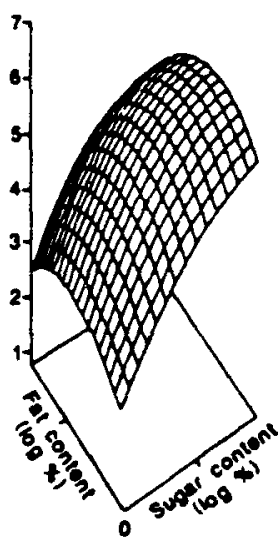

Bunac

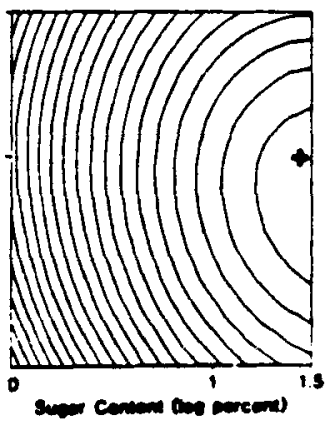

ANORECTIC

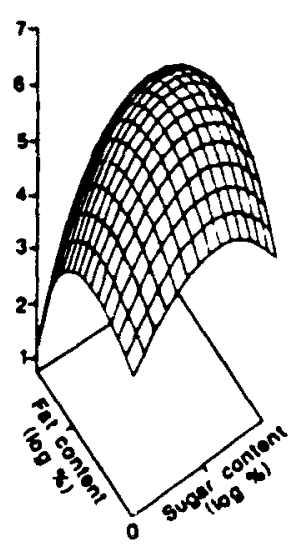

MORECTC

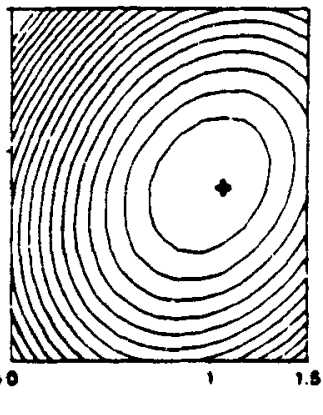

FIGURE 1. Hedonic response surfaces for the average subject expressed in terms of threedimensional projections (top) and isohedonic contours (bottom). The axes represent sucrose ( $\mathrm{x}$ axis) and lipid content ( $y$-axis) of the stimuli, expressed as log percent wt/wt. Regions of optimal preference as predicted by the Response Surface Model are denoted by + signs (From Drewnowski et al. ${ }^{16}$ Reprinted by permission.)

fat were approximately the same both before and after weight regain, as summarized in TABLE 3.

One potential explanation for this stability of taste response is incomplete clinical recovery. Physiological or neuroendocrine impairments often persist following the recovery of body weight and the taste response may be equally slow to adjust. ${ }^{16}$ Other investigators have also observed that affective responses are surprisingly resistant to changes over time. ${ }^{44}$ Neither weight gain ${ }^{16,44}$ nor moderate caloric restriction and weight $\operatorname{loss}^{45}$ have been linked with significant changes in preference for sweet taste.

Measures of hedonic response to sweetness following the consumption of an intensely sweet preload have also failed to reveal significant changes in sweet preference following gains or losses in body weight. In one early study, ${ }^{46}$ anorectic women showed slightly elevated preferences for sweet taste relative to controls following the consumption of a $400-\mathrm{kcal}$ meal. However, elevated preferences for sweet taste were also ob- 

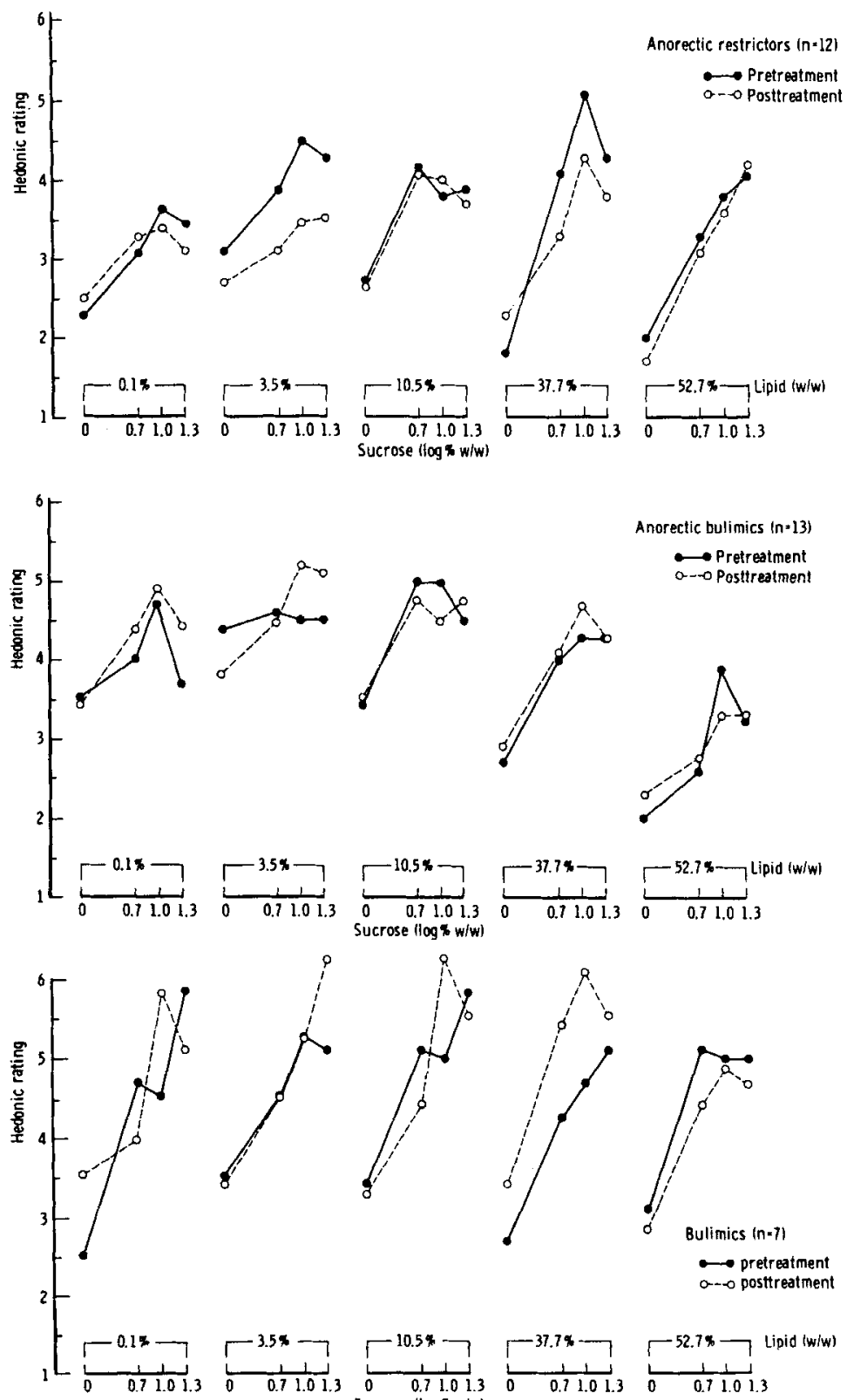

$\leftrightarrow$ pretreatment

a-o posttreatment
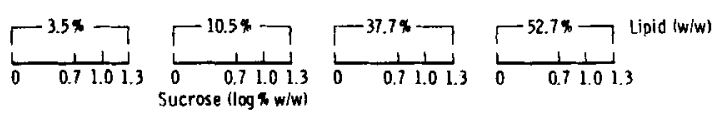

FIGURE 2. Mean hedonic preference ratings as a function of sucrose content for each type of dairy product. Sucrose levels are plotted as $\log$ percent wt/wt. The data are for anorectic restrictor patients (top panel), anorectics with bulimia (middle panel), and bulimic patients (bottom panel) tested before and after treatment. 
TABLE 3. Optimal Stimulus Composition Pre- and Post-Treatment ${ }^{a}$

\begin{tabular}{|c|c|c|c|c|c|}
\hline \multirow[b]{2}{*}{ Group } & \multirow[b]{2}{*}{$n$} & \multicolumn{2}{|c|}{ Pretreatment } & \multicolumn{2}{|c|}{ Post-Treatment } \\
\hline & & $\underset{\%}{\text { Sugar }}$ & $\begin{array}{c}\text { Fat } \\
\%\end{array}$ & $\underset{\%}{\text { Sugar }}$ & $\begin{array}{c}\text { Fat } \\
\%\end{array}$ \\
\hline Anorectic & 25 & 12.7 & 16.5 & 10.6 & 17.8 \\
\hline Bulimic & 7 & 15.3 & 27.9 & 13.3 & 19.3 \\
\hline Normal weight & 16 & 9.1 & 28.7 & - & - \\
\hline
\end{tabular}

${ }^{a}$ From Drewnowski et al. ${ }^{16}$ Reprinted by permission.

served in a follow-up study conducted with the same patients one year following the regain of target body weight. ${ }^{44}$ Similarly, studies on obese persons failed to show differences in satiety aversion to sucrose between underweight, normal-weight, and overweight persons. ${ }^{42.43}$ It may be that the pleasure response to sweet taste is not a reliable measure of distance from set-point as indexed by fluctuations in body weight. Individual profiles of taste responsiveness appear to be a stable trait that is resistant to short-term shifts in body weight.

\section{CENTRAL MECHANISMS}

Taste responsiveness may be linked to indices of metabolic status other than body weight. The relationship between serotonin metabolism, affective disorders, and carbohydrate craving in bulimia has been proposed by a number of previous studies. ${ }^{12.27}$ It should also be noted that neuroendocrine dysfunctions and deficits of hypothalamic-pituitary regulation of the adrenal axis may persist for months following weight regain. ${ }^{47}$ Both have been linked with altered food preferences and diet choices. Elevated endogenous opioid levels in anorexia nervosa and bulimia ${ }^{2,48}$ have in some cases been reported to decline following weight regain.

The relationship between opioid peptides, the pleasure response to sweet taste and uncontrollable binges on sweet foods offers a new and promising avenue of research. Studies on laboratory animals have linked endogenous opioids with nutrient selection, eating behavior, and obesity in both rats and mice. ${ }^{8.36}$ Opioid peptides are known to mediate the biological response to stress and are thought to modulate the pleasure response to sweetness. ${ }^{31}$ Dieting anorectic and bulimic patients have been reported to show elevated levels of $\beta$-endorphin ${ }^{48}$ and elevated preferences for the taste of sweet solutions. ${ }^{16,38}$ It remains to be seen whether taste responsiveness mediates the presumed link between physiological factors, bulimic episodes, and the selection of sweet foods during a binge.

\section{REFERENCES}

1. Halmi, K. A. \& J. R. FalK. 1981. Common physiological changes in anorexia nervosa. Int. J. Eating Disord. 1: 16-27.

2. WeINER, H. 1985. The physiology of eating disorders. Int. J. Eating Disord. 4: 347-388.

3. Russell, G. F. M. 1979. Bulimia nervosa: An ominous variant of anorexia nervosa. Psychol. Med. 9: 429-448.

4. Johnson, C., C. Lewis \& J. Hagmann. 1984. The syndrome of bulimia: Review and synthesis. Psychiatr. Clin. N. Am. 7: 247-272.

5. CASper, R. C., E. D. Eckert, K. A. Halmi, et al. 1980. Bulimia: Its incidence and clinical importance in patients with anorexia nervosa. Arch. Gen. Psychiatry 37: 1030-1035. 
6. Garfinkel, P. E., H. Moldofsky \& D. M. Garner. 1980. The heterogeneity of anorexia nervosa: Bulimia as a distinct subgroup. Arch. Gen. Psychiatry 37: 1036-1040.

7. Johnson, C. L., M. K. Stuckey, L. D. LewIs \& D. M. Schwartz. 1982. Bulimia: A descriptive survey of 316 cases. Int. J. Eating Disord. 2: 3-16.

8. Russell, G. F. M. 1967. The nutritional disorder in anorexia nervosa. J. Psychosom. Res. 11: $141-149$.

9. Taylor, M. E., R. W. Lawrence \& K. G. D. Allen. 1986. Nutritional assessment of college age women with bulimia. Int. J. Eating Disord. 5: 59-74.

10. Beumont, P. J. V., T. L. Chambers, L. Rouse \& S. F. Abraham. 1981. The diet composition and nutritional knowledge of patients with anorexia nervosa. J. Hum. Nutr. 35; 265-273.

11. KaYe, W. E., M. H. Ebert, H. E. Gwirtsman \& S. Weiss. 1984. Differences in brain serotonergic metabolism between nonbulimic and bulimic patients with anorexia nervosa. Am J. Psychiatry 141: 1598-1601.

12. Rosenthal, N. E. \& M. M. HefFerman. 1986. Bulimia, carbohydrate craving and depression: A central connection? In Food Constituents Affecting Normal and Abnormal Behaviors. Nutrition and the Brain, Vol 7. R. J. Wurtman \& J. J. Wurtman, Eds.: 139-166. Raven Press. New York.

13. Logue, A. W., K. R. Logue \& K. E. Strauss. 1983. The acquisition of taste aversions in humans with eating and drinking disorders. Behav. Res. Ther. 21: 275-289.

14. Sherman, B. M.\& K. A. Halmi. 1977. The effect of nutritional rehabilitation on hypothalamic-pituitary function in anorexia nervosa. In Anorexia Nervosa. R. A. Vigersky, Ed. Raven Press. New York.

15. Rodin, J. 1987. Sweetness and eating disorders. In Sweetness. J. Dobbing, Ed.: 193-204. Springer-Verlag. Berlin.

16. Drewnowski, A., K. A. Halmi, B. Pierce, J. Gibss \& G. P. Smith. 1987. Taste and eating disorders. Am. J. Clin. Nutr. 46: 442-450.

17. Nakai, Y., F. Kinoshita, T. KoH, S. TsujII \& T. Tsukada. 1987. Taste function in patients with anorexia nervosa and bulimia nervosa. Int. J. Eating Disord. 6: 257-265.

18. JJRIK-BABB, P. \& J. L. KATZ. 1988. Impairment of taste perception in anorexia nervosa and bulimia. Int. J. Eating Disord. 7: 353-360.

19. Hurst, P. S., J. H. LACEY \& A. H. Crisp. 1977. Teeth, vomiting and diet: A study of the dental characteristics of seventeen anorexia nervosa patients. Postgrad. Med. J. 53: 298-305.

20. Miles, D. A., B. E. GregG, B. J. Glass \& M. L. VAN Dis, 1985. Bulimic erosion: Dental management and report of cases. J. Can. Dent. Assoc. 10: 757-760.

21. CRISP, A. H. 1967. The possible significance of some behavioral correlates of weight and carbohydrate intake. J Psychosom. Res. 11: 117-131.

22. CRISP, A. H. \& R. S. KaluCY. 1974. Aspects of the perceptual disorder in anorexia nervosa. Br. J. Med. Psychol. 47: 349-361.

23. Drewnowski, A., B. Pierce \& K. A. Halmi. 1988. Fat aversion in eating disorders. Appetite 10: 119-131.

24. O'Connor, M. A., S. W. Toyuz, S. M. Dunn \& P. J. V. Beumont. 1987. Vegetarianism in anorexia nervosa? A review of 116 consecutive cases. Med. J. Aust. 147: 540-542.

25. HuSE, D. M. \& A. R. LuCAS. 1984. Dietary patterns in anorexia nervosa. Am. J. Clin. Nutr. 40: 251-254.

26. American Psychiatric Association Committe on Nomenclature and Statistics. 1980. Diagnostic and Statistical Manual of Mental Disorders (DSM-III). Washington, DC.

27. Kaye, W. H., H. E. G. Wirtsman, D. T. George, S. R. Weiss \& D. C. Jimerson. 1986. Relationship of mood alterations to binging behaviour in bulimia. Br. J. Psychiatry 149: 479-485.

28. Mitchell, J. E., R. L. Pyle \& E. D. Eckert. 1981. Frequency and duration of bingeeating episodes in patients with bulimia. Am. J. Psychiatry 136: 835-836.

29. Mirchell, J. E. \& D. C. LAine. 1985. Monitored binge-eating behavior in patients with bulimia. Int. J. Eating Disord. 4: 177-183.

30. KissilefF, H. R., B. T. Walsh, J. G. Kral \& S. Cassidy. 1986. Laboratory studies of eating behavior in women with bulimia. Physiol. Behav. 38: 563-570.

31. Rosen, J. C., H. Leitenberg, C. Fisher \& C. Khazam. 1986. Binge-eating episodes in 
bulimia nervosa: The amount and type of food consumed. Int. J. Eating Disord. 5: 255-267.

32. Leon, G. R., K. Carroll, B. Chernyk \& S. Finn. 1985. Binge-eating and associated habit patterns within college student and identified bulimic populations. Int. J. Eating Disord. 4: 43-57.

33. DREwnowsKI, A. 1987. Changes in mood following carbohydrate consumption. Am. J. Clin. Nutr. 46: 703.

34. Abraham, S. F. \& P. J. V. Beumont. 1982. How patients describe bulimia or binge eating. Psychol. Med. 12: 625-635.

35. Pirke, K. M., J. Pahl, U. Schweiger \& M. W arnhoff. 1985. Metabolic and endocrine indices of starvation in bulimia: A comparison with anorexia nervosa. Psychiat. Res. 15: 33-39.

36. CASPER, R. C., B. KiRschner, H. SANDSTEAD, et al. 1980. An evaluation of trace metals, vitamins, and taste function in anorexia nervosa. Am. J. Clin. Nutr. 33: 1801-1808.

37. Drewnowski, A., F. Bellisle, P. Aimez \& B. Remy. 1987. Taste and bulimia. Physiol. Behav. 41: 621-626.

38. Drewnowski, A. 1986. Sweetness and obesity. In Sweetness. J. Dobbing, Ed.: 177-192. Springer-Verlag. Berlin.

39. Drewnowski, A., J. B. Brunzell, K. Sande, P. H. Iverius \& M. R. C. Greenwood. 1985. Sweet tooth reconsidered: Taste responsiveness in human obesity. Physiol. Behav. 35: $617-622$.

40. Drewnowski, A. \& M. R. C. Greenwood. 1983. Cream and sugar: Human preferences for high-fat foods. Physiol. Behav. 30: 629-633.

41. Cabanac, M. \& R. Duclaux. 1970. Obesity: Absence of satiety aversion to sucrose. Science 168: $496-497$.

42. Gilbert, D. G. \& R. L. HaGen. 1980. Taste in underweight, overweight, and normal-weight subjects before, during, and after sucrose ingestion. Addict. Behav. 5: 137-142.

43. Grinker, J. 1978. Obesity and sweet taste. Am. J. Clin. Nutr. 31: 1078-1087.

44. Garfinkel, P. E., H. Moldofsk y \& D. M. Garner. 1979. The stability of perceptual disturbances in anorexia nervosa. Psychol. Med. 9: 703-708.

45. Rodin, J., H. R. Moskowitz \& G. A. BRAY. 1976. Relationship between obesity, weight loss, and taste responsiveness. Physiol. Behav. 17: 391-397.

46. Garfinkel, P. E. 1974. Perception of hunger and satiety in anorexia nervosa. Psychol. Med. 4: 309-315.

47. Gold, P. W., H. Gwirtsman, P. C. Avgerinos et al. 1986. Abnormal hypothalamicpituitary-adrenal function in anorexia nervosa. N. Engl. J. Med. 314: 1335-1342.

48. Kaye, W. H., D. Pickar, D. Naber \& M. H. Ebert. 1982. Cerebrospinal fluid opioid activity in anorexia nervosa. Am. J. Psychiatry 139: 643-645.

49. Margules, D. L., B. Moisset, M. J. Lewis, et al. 1978. Beta-endorphin is associated with overeating in genetically obese mice (ob/ob) and rats $(\mathrm{fa} / \mathrm{fa})$. Science 202: 988-991.

50. Blass, E. M. 1986. Opioids, sugar and the inherent taste of sweet: Broad motivational implications. In Sweetness. J. Dobbing, Ed.: 115-126. Springer-Verlag. Berlin.

\section{DISCUSSION}

Dr. Harry Kissileff (St. Luke's-Roosevelt Hospital, New York): Adam, it was mentioned earlier by Dr. Linda Bartoshuk that fats have volatiles in them that produce odors, but I noticed when you mentioned all the different factors that could discriminate between your various mixtures, you did not say anything about the odor. I think odor is an important component in this carbohydrate-craving phenomenon. If you think about all the foods that are listed, there aren't only fats and sugar mix- 
tures, there are the odor-producing chemicals in them that might be the most important component. Have you any thoughts on that?

Dr. Adam Drewnowski (University of Michigan, Ann Arbor, MI): Yes, it is very important. In milk you have esters and lactones, and you have the volatile components. Of course it gets much richer if you are dealing with solid fat, shortening, oils, and so on. In this particular set of studies, we did not use nose clips or any other ways of removing sensory cues other than taste or texture. Dr. Rose Marie Pangborn has done studies like that, and there are weak cues from odor. However, we wanted to have natural conditions and have subjects taste the stimuli under such conditions as they normally would eat sugar and fat foods. But in some cases, I should note, the actual odors in fats are really not all that pleasant. In fact because of the odor, there may be an aversion to specific types of fats in those combinations of sugar and fat. It's a very good point.

DR. BARBARA Rolls (Johns Hopkins University, Baltimore, MD): In your fat preference, obviously, viscosity could be a factor, and I know you have thought about that. I am wondering if we know anything else about texture in relation to eating disorders. I understand texture is an important factor in influencing intake in anorectics and bulimics.

DR. DREwnowski: Anorectics often seem to subsist on a diet of what they call safe foods that seem to be mostly crunchy vegetables. However, many bulimic binges specifically include soft, creamy semi-solid foods, and one of the reasons that has been mentioned is that such foods may facilitate vomiting after the binge. Toward the end of the binge, texture of the food sometimes changes. There is a great deal of drinking of diet sodas and patients eat softer foods. So it is possible that while taste may be the initial stimulus, the texture of foods also plays a role. 